\title{
ACTS OF AGENCY IN ENGLISH LANGUAGE LEARNING EXPERIENCE
}

\author{
Noor Saazai Mat Saad1 *, Hamidah Yamat ${ }^{2}$, Harison @ Hanisa Mohd. Sidek ${ }^{3}$, \\ Hazleena Baharun, Muzhafar Mohd. Idrus
}

\author{
1Dr.,Universiti Sains Islam Malaysia, Malaysia, nmatsaad@gmail.com \\ ${ }^{2}$ Assoc. Prof. Dr., Universiti Kebangsaan Malaysia, Malaysia, hamidah yamat@ukm.edu.my \\ ${ }^{3}$ Assoc. Prof. Dr., Universiti Sains Islam Malaysia, Malaysia, harison@usim.edu.my \\ Dr., Universiti Sains Islam Malaysia, Malaysia, hazleena@usim.edu.my \\ Dr., Universiti Sains Islam Malaysia, Malaysia, muzhafar@usim.edu.my \\ ${ }^{*}$ Corresponding Author
}

\begin{abstract}
Successful language learners exercise their agency as they experience learning or acquiring the target language. Their agency acts as the push from within themselves; influenced by the need of an end to be fulfilled and the action taken is within the permitted perimeter of the environment. This is evident in the current study on nine international students whose insights were captured through document analysis of their online postings and interviews. Findings revealed that these international students exercised their agency by making relentless efforts in employing language learning strategies despite the challenges they faced to become better learners of the English language. Further findings illustrating agency were investment and imagined community. Although both investment and imagined community concur with existing literature, the findings from this study further highlight 'experience' as an impetus for investment in English language learning.
\end{abstract}

Keywords: agency, English language learning experiences, imagined community, international students, investment

\section{INTRODUCTION}

The meaning of agency is explained by Parson as cited in Davies (1990, p. 343) as planning "a line of action, know[ing] how to achieve it and [having] the power and authority and right to execute it". Hence, having or exercising one's agency suggests the push from within oneself that is influenced by the need of an end to be fulfilled and the action taken is within the permitted perimeter of the environment. This is in line with Bandura's agentic perspective $(2001 ; 2005 ; 2006)$ as he proposed in the Social Cognitive Theory (SCT). He mentions that one becomes agentic or does things intentionally as to fulfil the goal set. In exercising one's agency, one can resist, negotiate, change and transform oneself (Pavlenko \& Blackledge, 2004) in order to meet the goal.

The notion of agency in the preceding paragraph is what Davies (1990) terms as traditional or agonistic agency where the main actor is the person himself. She, on the other hand, has accentuated another important aspect of agency. Instead of just between the actor and the environment, she focuses on the idea of how the actor is positioned by 'interactive others'; the people in the environment have the power to allow or disallow the person to exercise his/her agency. This is based on her detailed analysis on the first few minutes in a classroom where it showed that although the students had agency; it was the teacher who actually allowed or disallowed the students to exercise the agency. This is a very interesting and fecund view on agency but the delimitation of 
this study is on personal human agency as posited by Bandura $(2001 ; 2005 ; 2006)$ where the power lies in the person himself/herself.

This paper reports on agency exercised by the international students in their English language learning in an institution. It is a part of a bigger study on the English language learning experiences of international students in Malaysia. With the research question of : How do the international students exercise their agency in their English language learning in Malaysia, this paper comprises the methodology, the selection of the participants, the findings or the themes together with related discussion and it ends with a summary. However, to situate agency in the academic setting, a literature review focusing on previous studies on agency therefore comes first.

\section{LITERATURE REVIEW}

In reference to studies by Tran (2007) and Kettle (2005) on international students' (ISs) acculturation process, agency might be the element that makes a difference in a person's acculturation process. Tran (2007) followed six ISs undergoing their studies in an Australian university. She studied their writing activity in doing their assignments. She interviewed the students and the writing lecturers involved. In her findings she highlighted the agency exercised by the students in completing the assignments.

Similarly, Kettle (2005) reported on a journey of an IS by the name of Woody. Woody is from Thailand and he was a teacher in his home country. Thus, it is also a story about how he negotiated his way through to be accepted as a member and student in the education community in his university and at the same time retain his Thai-ness. Kettle also stresses on agency as playing the role in facilitating the negotiation. The agency in both Tran (2007) and Kettle's (2005) studies show that in exercising one's agency to realise the goal set, one has to consider assistance and constraints in the environment. The assistance and constraints in the environment include the people and artefacts around him/her.

There are two elements seen to be prevalent in their exercise of agency: imagined community and investment. Both are evinced in studies by Arkoudis and Love (2008), Gu (2008), Gao et al. (2008), Pierce (1995), and Trent (2008). The former two are samples of studies discussing imagined community while the rest touch on investment. As an illustration of imagined community, Arkoudis and Love (2008) find that the lack of use of English among students in a Mathematics class is due to their 'imagined community' because they foresee that English will not be totally important in their future. In other words, they visualise that English will be secondary when they pursue their future endeavours in Mathematics, thus there is little need for them to be speaking the language.

On the element of investment, a study by Gao et al. (2008) is a good example. It is about Chinese students from Mainland China studying in a Hong Kong university setting up a group to practise and use English to upgrade their command of the language. The first writer, who is also one of the participants, reveals the effort put in and the time spent in their motivation to being competent in the language. Motivation is conceptualised as investment by Norton Peirce (1995) in relation to agency. Furthermore, a qualitative study conducted by Oxford and her student colleagues in 2007 and reported in Oxford (2011) discovers that the student's lack of ability to handle second language learning crisis is due to among others, lack of 'investment'.

A write up by Lantolf and Pavlenko (2001) on agency highlights two other important tenets. Firstly is about history or experiences that can also be a factor to the agency exercised by a learner. The second tenet is about agency being dynamic. It is not static as it changes according to situation and need. Both aspects are important because the participants in this study are adults who have gone through the early part of their lives elsewhere and their goals might have changed.

In encapsulation, using the definition by Bandura $(2001 ; 2005 ; 2006)$ that posits personal human agency and looking into the studies cited; it can be surmised that there is connection between agency and the successes and challenges in their English language learning.

\section{THE METHODOLOGY}

This study is under the qualitative paradigm where document analysis and interview were the two methods employed. It was a multiple-case study with the primary data coming from the participants' online postings on Google+ (document analysis). More information on the online postings activity has been reported elsewhere (refer to Noor Saazai et al., 2014). The information from two postings for ten weeks became the input in the two rounds of interviews with the participants and triangulated by the interviews with the lecturers involved in teaching the participants. The data collection procedures began with the first round of interview with the participants. Then, the participants were requested to post online (1) the weekly report on their successes and challenges faced in learning English, and (2) the response to the weekly topic (refer to Appendix). Their online 
postings were conducted for ten weeks. Then, the participants were invited for the second round of the interview. The input from the postings was discussed during the interview. The lecturers were also interviewed after that. The data were analysed following the 6-step thematic analysis as stipulated by Braun and Clarke (2006). The data analysis was managed by utilising ATLAS.ti, a computer assisted qualitative analysis software (CAQDAS).

\subsection{The Participants}

There were nine student participants and their three lecturers involved. The former were all international students from Iraq (3), Iran (1), Libya (1), Algeria (1), Palestine (1), Bahrain (1) and Indonesia (1), while the latter were all Malaysians. The student participants were all pursuing their postgraduate degrees in an institution in Malaysia, and at the time of the study they were undertaking an English language proficiency course (ELPC) taught by the three lecturers. Six were from the sciences whereas three were from the social sciences. Their ages ranged from 22 to 39 years old, and three of them were females while six of them were males.

\section{THE FINDINGS/THE THEMES}

The research question (RQ) of 'How do the international students exercise their agency in their English language learning in Malaysia' required the discussion of both 'how' and 'why'. The data revealed the 'how' question through the 'actions' of the participants while the 'why' question was through the identification of the reasons for the participants' agentic behaviour. By doing so, it presents the process of how they exercised their agency as they experienced English language learning. Hence, there are three main findings for the RQ: actions, investment, and imagined community. Figure 1 is a network view, an output from ATLAS.ti that displays the findings (themes, subthemes and sub-subthemes).

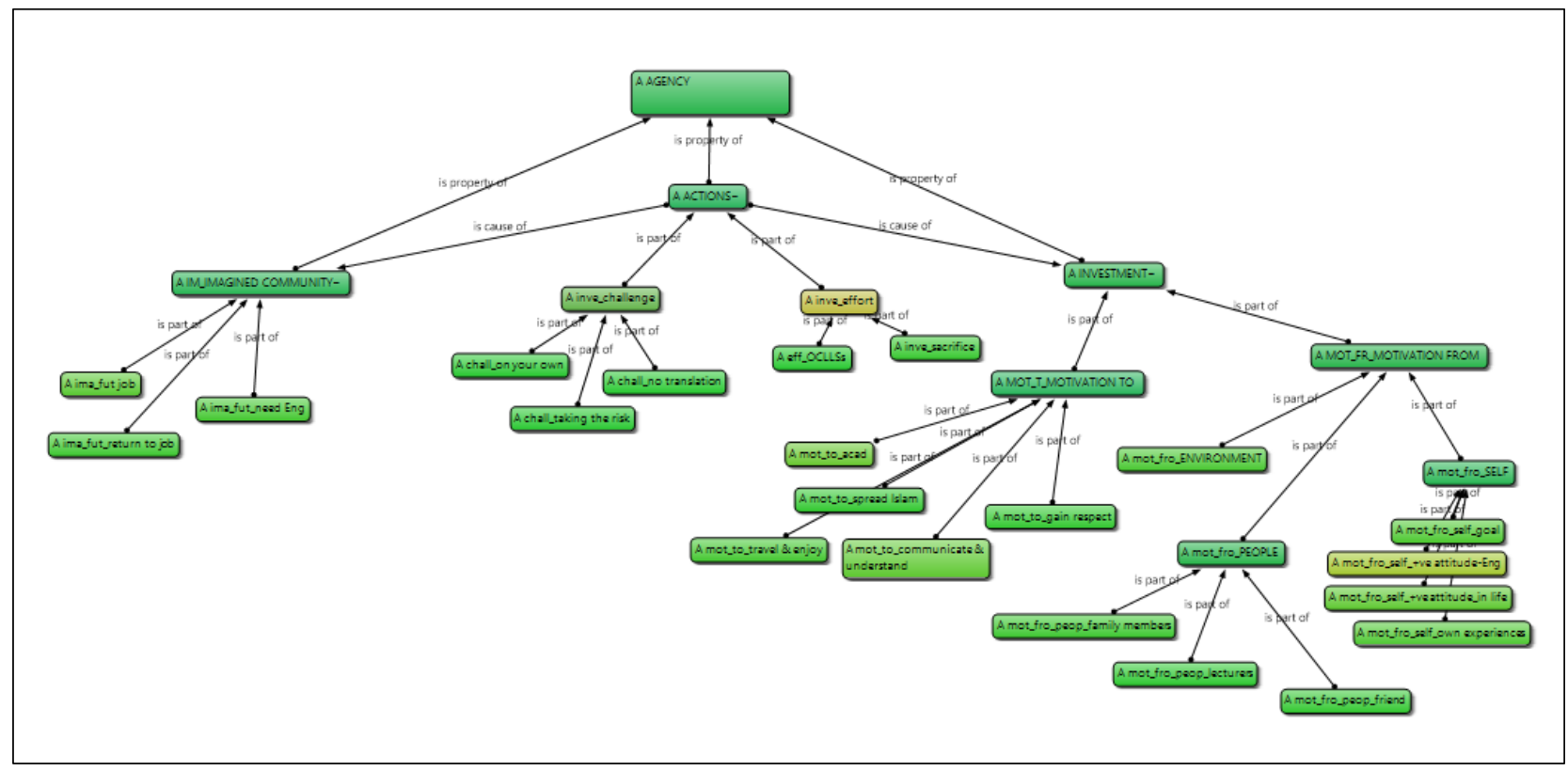

Figure 1 Findings for the $\mathrm{RQ}$ : actions, investment, and imagined community

Figure 1 depicts the three main themes for agency. The discussion in this section begins with 'actions'. It is then followed by 'investment' and lastly 'imagined community'. The arrangement is such because 'actions' are the portrayal of how agency is exercised by the participants whereas the other two themes are their reasons that became the push and pull factors for the agency exercised. Together they form a process of how these participants exercised agency in the successes and challenges faced in their English language learning.

Each theme begins with a visual on the subtheme and sub-subthemes. It is then discussed by assigning data extracts from the online postings and interviews to give a vivid picture of the theme; thus, it is taken verbatim (errors included) and the source is indicated, for example 'Basri, op3A' means the information is from Basri (pseudonym) and taken from his online posting number 3, round 1(A). Further, 'int_1' refers to interview round 1 for student participants. In the interview exchanges, the dialogues by the participants are in bold. Each theme ends with a discussion. 


\subsection{Theme 1 - Actions}

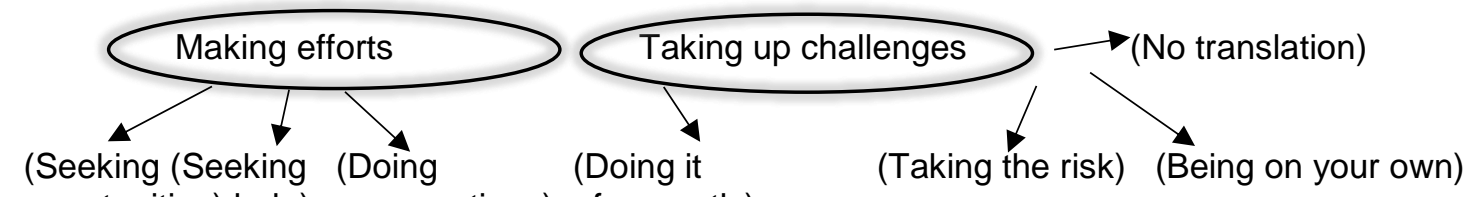

opportunities) help) preparations) frequently)

One becomes agentive or does things intentionally to fulfill the goal set. The goal of the participants in this study varied but generally, their short-term goal in relation to English at the time of the study was to complete and pass their ELPC. The actions are not just driven by goal-fulfilling motives but also influenced by the environment which consists of people and artefacts around the participants.

This answers the 'how' part of the research question. Therefore this section presents the actions that the participants took in exercising their agency. There are two subthemes that emerged from their reported learning experiences - making efforts and taking up challenges.

In the first subtheme, participants showed relentless efforts in learning English. Reflecting on the deliberation of their successes, they sought opportunities to use English when they got the chance, and they also sought help in learning the language by attending extra classes, using dictionary, and asking help from other people. Moreover, participants also did preparations and revisions in order to be successful at doing tasks. Another obvious effort was when they reported doing an activity frequently.

Firstly, these participants sought for opportunities to use /learn English anywhere. Nabil, for example, took chance to read at the shopping mall. He wrote : "In shopping mall: For example, try to read product details in English It helps to get a feel of reading and also read the things written in the stores" (Nabil, op3A). He also talked to people at the bus stop: "i try to speak English also when $i$ waiting the buses i try to talk with Malaysians and Chinese and any one can talking English" (Nabil, op1B). Besides that, he "opened a Group in (WhatsApp program) with [his] friends and [they] talking in English only to improve [themselves]" (Nabil, op2B). Mohsin also took advantage of the technology by communicating on the social networking site. He mentioned that "I have three foreigner friends. Sometimes I see them in class and I speak with them after class. Most of the time I connect with them on Facebook and comment for each other on our photos or our status" (Nabil, int_2).

Moreover, Faizal was seen to exercise agency when he grabbed the chance to practise English when opportunity presented itself. He shared the two incidents when he went to the extent of asking questions even though he already knew the answer. He wrote:

Last week I go from UKM to KL sentra by KTM after that I take monorail trian go to Bokit Bentang and always ask people how I can go to this place or that place even the places I know it just for practicing after that I go to the airport by the train then return to my hostel"

(Faizal, op1B).

Then he did it another time on the way to the airport. He said, "one time I take my friend to the airport. So I ask where is I can put my bag, I see where I can but I ask and I go to another person and ask" (Faizal, int_1).

As seen in the preceding paragraph, the efforts shown by the participants in exercising their agency in English language learning have led to positive progress and good feelings which suggest successes. However, when faced with challenges, their efforts can be seen through sacrificing. In terms of lack of time, Fairus had to sacrifice her sleep in order to do well in her online postings by searching for information online. She said, "I didn't have free time but I take from sleeping time at the night" (Fairus, int_1). Basri also complained, "Sometimes I sleep late, to do my assignments, to translate, to posting" (Basri, int_2). As for the reported challenge of having less opportunity to use English due to the nature of the situation when one has to use own language, Shamsulwahab showed his effort by sending his wife for English tuition with a neighbour, and his daughter to Smartreader - a preschool that uses English as a medium of instruction. This is because he planned to dedicate time to speak English with his family members. He strategised to "determine 1 hour or 2 hours to speaking" at home (Shamsulwahab, int_1).

In addition, Shamsulwahab also mentioned about setting rules in order to ensure that he would speak English even with his countryman. He said, "in my room I have 2 students, one from Iranian and another Iraqian people. We say in the room I and my friend don't speak Arabic, should be speaking English with the Iranian people for all time in my room we speaking in English" (Shamsulwahab, int_2). 
Next, these participants sought help from people. Some got people engaged in a conversation like relayed by Faizal earlier (on the monorail and on the way to the airport). In addition, he also talked to UKM guards. He penned: "last week I wait my friend to take me from university in the gate of UKM so I sat with the guards and we still talking maybe $30 \mathrm{~min}$ " (Faizal, op2B). Besides that, these participants also approached other people to seek help about their assignment/work. For example, Fairus asked her senior to help her in doing her proposal writing, specifically the objectives. This is seen in the exchanges below:

when I see old proposal it has 'to', 'to', 'to'.

You follow?

\section{I remember that the thing that I learn from the proposal I should write to for the objectives}

So you also check when Dr Saleh gave back, the mistake here you didn't understand what you should do. But you check your friend's proposal? Your friend in class?

Out. From..not different. The student who before me.

Your senior sort of

Yes. They finished their proposal. (Fairus, int_2).

Participants exercised agency by getting other people involved in their language learning activities. This is vividly as shown especially by Faizal as he engaged strangers in his conversations. However, Faizah and Nabil showed more courage in exercising their agency when they asked their friends to correct their language. Faizah admitted in the extract below:

\section{If I with my friend, he tell me this is wrong, this is wrong, not like this}

And you like people to correct you

Ya

(Faizah, int_2)

In the quest to become better at English, Nabil, too had a friend correcting his mistakes in his 'Whatsapp' group. He said: "Only 5 friends. One of them is now in Canada. And he knows English very well. When we have mistake or wrong, he will correct, all of it" (Nabil, int_1).

The next evidence of effort shown in the employment of agency is in their preparations and revisions. Imran prepared for his everyday task by preparing possible questions. He wrote: "when I came to the university had to be an attempt to speak English, and that was by preparing questions and get ready for the answers expected in my life daily,And also by going to the shops to buy" (Imran, op2B). Many also talked about preparations in conjunction with their in-class oral presentation activity. Both Shamsulwahab and Fairus searched for points and practised for their presentations. Fairus said that she "should research about first about the information" (Fairus, int_2) and Shamsulwahab ended his list of preparations for his oral presentation when he announced that "the last step, practice, practice, practice my assignment [presentation]" (Shamsulwahab, op9A).

In terms of doing revision, Mohsin utilised technology to help him remember words learnt. He said: "For remembering the words I wrote them on my mobile and tablet and I have been repeating them in the way of university" (Mohsin, int_2). Imran, on the other hand, made a connection between newly-found words and his own vocabulary in his mother-tongue. He shared: "New words do I learning it by linking up with the Arabic words" (Imran, int_2).

Besides seeking opportunities, seeking help, doing preparations and revisions, these participants exercised their agency by doing the activities frequently. Most highlight on doing the activities daily. Nabil said: "Sometimes every day I send message in English" (Nabil, int_1). He was referring to his conversation in the 'Whatsapp' group. Basri talked about collecting one word daily. He mentioned "get everyday one words, it is good" (Basri, int_1). In addition, Fairus wrote: "Reading books or novels or newspaper and magazines at least half an hour daily" (Fairus, op3A).

Referring to Fairus' statement, she did not only stress on daily but also on the duration - half an hour. She further reported spending time on searching for information in completing her task. She were actually complaining when she said: "Each time you gave us topic, I must search in many websites, maybe 10 more, I sit for 2 to 3 hours searching" (Fairus, int_2). Moreover, Faizah admitted: I practice for this [reading aloud] for my friend even if I have 5 minutes, I read" (Faizah, int_2). What Faizah did is a reflection of how environment or situation affects agency, as due to the challenge of time constraint, she still did what she could even in the short time that she had.

The second subtheme of how the participants exercised agency is by taking up challenges or in other words 
- when they challenged themselves. Basri announced that"l become out to challenge my language" (Basri, int_1). This is also as appropriately worded by Dr Kaseh when she said that her students (including the 9 participants) would love to put themselves "at the deep end of the pool" (Dr. Kaseh_int). The data revealed 3 types of challenges that they put themselves through. The challenges are termed as 'no translation', 'taking the risk' and 'being on your own'.

Translation is prevalent among these participants. Therefore, it can be inferred that doing translation can assist them and they might have become dependent on doing translation in their English language learning. Furthermore, Shamsulwahab (int_1) and Nabil (int_1) admitted that "[doing translation is fast]". Thus, when they omitted any translation activity in their language learning, it seems that they have challenged themselves to be independent. Nabil wrote, "so I'm trying to develop myself in English, like I trying to write full paragraph without using translator" (Nabil, op3B). Basri admitted that he tried avoiding doing translation. He wrote, "in my writing assignments I always try to not use any dictionary, or google translate" (Basri, op9A).

Besides staying away from doing translation in their academic works, some participants also avoided referring to subtitles as they provide the translation for the dialogues in the movie or television programme. Nabil reported that "[he] watch[ed] the movie in English without translation into Arabic" and exclaimed "I understood the story of the film fully" (Nabil, op6B). In the same light, Fairus watched cartoons by just "listening to what they say and not read the subtitles" (Fairus, op2B).

Avoiding translation is a challenge for them because when victorious in doing so, it brought a sense of achievement to them. Nabil saw this as a way "to develop [him]self in English" and "[he] had a great experience....watch[ing] the movie in English without translation into Arabic" (Nabil, op6B). Fairus also had a similar thought. She felt that listening and watching the cartoons alone without reading the subtitles "was a good thing to do" (Fairus, op2B).

The second challenge has to do with taking risk. Shamsulwahab, Fatinmalik and Fairus shared their experiences crossing their own boundaries. The former two braved themselves to participate and present in international conferences while the latter did her presentation in class without preparation. Fairus wrote: "I challenged myself by not doing any prepare...[for] which I will talk about" (Fairus, op4B). Shamsulwahab mentioned that the paper presentation made him "daring to speaking in English because this first time I talk in English only in certain subject for 20 minutes" (Shamsulwahab, op1B). Although Fairus announced that she did not do any preparations, the cases were different for Shamsulwahab and Fatinmalik. Shamsulwahab consulted his supervisor, "[amended his poster and slides based on his supervisor's recommendations and even practised in front of him]" (Shamsulwahab, int_1). Besides presenting in the international conference, Fatinmalik was also chosen to be the chairperson for one of the sessions. Although reluctant at first as that was her first conference, she took up the challenge and in preparation; she went to earlier sessions to see some examples. She shared: "the first day I look to the chairperson how they do..did, how they talk, so, the second day when I do my)...it is no problem" (Fatinmalik, int_2).

The third challenge that is taken up by the participants is 'being on your own'. Almost all of the participants believed that when they are on their own especially in a foreign country, they would be able to be better at least in speaking English. This is reported in their online postings in reaction to the topic of 'If I had 1 million USD, what would I do to improve my English'. Some participants like Faizal, Faizah, and Mohsin observed people they know becoming better in English when they have been on their own in a foreign country. They saw their cousins (Faizal, int_1), brother (Faizah, int_2) and sister (Mohsin, int_1) doing much better in English when they have been in Malaysia for quite some time. Faizal also shared his brother's success story in Ukraine (Faizal, int_2). Basri, on the other hand, witnessed a transformation of his Seychelles friend from knowing a few words to having the language that make him "can talk, can argue!" (Basri, int_1) after staying in a foreign country for some time. However, in Basri's case, the target language is not English, but Arabic.

Through own beliefs and observations, the participants felt that taking up the challenge to be on their own in a foreign country would benefit their language learning. Basri, on the other hand, had a first-hand experience in this. He was working from "8.30 to 4" (Basri, int_2) every day as an Arabic teacher in an international school where everything is in English and everyone speaks English (Basri, int_1). He announced, "Yeah, I become out to challenge my language" (Basri, int_1) and he did. He translated texts, spoke English to his students, his students' parents, his colleagues and also his principal. He viewed the school "like small country" (Basri, int_2) where English was used throughout. Thus, based on his own experience of successfully learning English in a foreign place, he repeatedly exclaimed that one has to be in the right attitude and environment to succeed in learning the language. In interview 1, he said in line 135: "If you want to learn English, you must use it even you didn't know. So you need someone to throw you in the area". The challenge is to speak English even though your language ability is limited. Similarly, he further asserted in line 181: "If you want to learn any language, you have to put yourself in the environment that you cannot talk [your own language]". The 'area' in 
data extract in line 135 and 'the environment that you cannot talk your own language' in line 181 are the same. In fact, he reiterated this idea in his second interview when he gave an example of someone who did not take advantage of being on his own in an Arab country. The exchanges are as seen below:

\section{Some of them errr...some students he didn't contact another student from another country, just with...}

Just with the same group of people

\section{Yeah. That's why after he goes back to his country, his Arabic is bad.}

(Basri, int_2)

The idea of being on your own and challenging yourself to be better in English has been pushed to a greater height by Faizal. Being on your own does not only make your language better but also makes you "be let's say...a man" (Faizal, int_2). He compared being in a foreign country to serving in a military. He indicated that each provides different kinds of hardships but both are difficult. Thus when asked if he had considered himself a man after spending a few months in Malaysia, he exclaimed "Yeah" and he explained his adaptations managing his life, food, money and communication (using both Bahasa Melayu and English) (Faizal, int_2).

To encapsulate, the participants exercised their agency to be and feel successful in their English language learning. At the same time, they also showed their agency in overcoming some of the challenges reported. In doing so, they made efforts and took up challenges to at least achieve their short-termed goal that was to pass their ELPC. Another essential part that warrants discussion when it comes to agency is the underlying reasons for the agency exercised. This is to be presented in the next two sections after the discussions.

\subsubsection{Discussion for Theme 1 - Actions}

Based on the anecdotal evidence above, it would be remiss not to draw attention to the 'power' that the participants emanated. Davies (1990) talks about power in her study on agency. However the 'power' that she refers to is about position - how one becomes agentic based on the position given by another person in the community. Her study was on the interactions of a teacher and his students on the first day of school. She documented that although the students had agency, it was the teacher who had the power to permit the students to exercise their agency by allowing that particular student to speak or to move on to the next student. As for this study, at one glance, it could be said that there was no interference of other parties in the participants' exercise of agency. However, seeing this from another angle, in some parts, it was the lecturers who empowered these participants by giving them assignments to complete and presentations to prepare for in the ELPC. Nonetheless, in many parts, it was the participants themselves who acted on their own, but adhering to their own limitations and constraints presented by the environment. Nabil, for example, had the intention to enrol for an English class organised by the British Council in Kuala Lumpur but due to time, expenses and distance he dropped the idea. He shared, "too much time, expensive also and also I don't have car. It is in KL centre. Many students say British Council is very good" (Nabil, int_1). So, he tried to be better at English by employing other strategies as reported in this study.

This is in tandem with Bandura's agentic perspective (2001). Exercising one's agency by reaching the goal set within the permitted environment reflects the agency that he proposes. According to Bandura's agentic perspective, (2001) an individual is responsible in materialising the aim that he or she has set by taking actions or not taking actions by considering the environment or situation around him/her.

\subsection{Theme 2 - Investment}

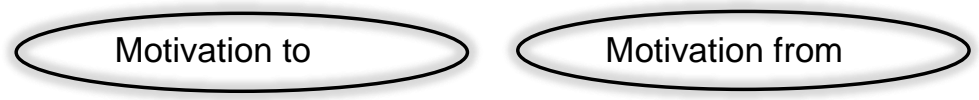

Investment is imbued by both social and historical aspects of an individual (Norton 1997). In other words, investment rises from a person's motivation to achieve multiple desires in his/her social environment and this is also based on his/her past experiences. Since motivation is the foundation of investment, the subthemes for investment are based on motivation - 'motivation to' and 'motivation from'. Extant literature on motivation has highlighted the dichotomies of intrinsic and extrinsic, and instrumental and integrative motivation. However, the data from this study can be more effectively discussed under the dichotomy of 'motivation to' and 'motivation from'. The former refers to the participants' effort to do an activity in order to achieve a goal which is related to the social and cultural (academic culture) environment that the participants were in; whereas the latter refers to the push that moves the participants to do an activity which is also connected to the participants' 
past experiences.

\subsubsection{Motivation to}

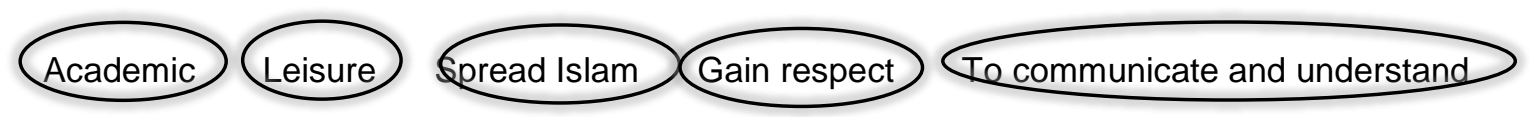

Participants admitted that they could achieve many goals by having a good or at least acceptable command of English. The goals are varied including to achieve academic standing, travel and enjoy (leisure), spread Islam, gain respect, and as simple as to communicate and understand.

Fairus, Fatinmalik, Nabil and Shamsulwahab reported that they needed English because their thesis would be written fully in English. Nabil expressed that his "thesis in English so [he] should learn English perfectly" (Nabil, int_1). This academic goal is also shared by Faizah who wrote that she needed English to "improve [her] skill to support [her] academic" (Faizah, op7B). In a similar vein, Fairus and Fatinmalik highlighted the importance of English as "the English language is the language of science" (Fairus, int_1), "medicine...and engineering, trade and technology, aviation and tourism, computer and Internet" and thus people need to "be familiar" (Fatinmalik, op3B) with the language. Moreover, she also added that English is needed in order for her to take part in international conferences (Fatinmalik, int_1). In brief, participants learned English to achieve academic goals involving producing a thesis in English, understanding information from various disciplines and participating in academic events.

The second reason for learning English is for leisure. They realised that English is needed when they travel or go abroad. Fatinmalik exclaimed that with English, "you can travel to any country in the world and enjoy" (Fatinmalik, op3B). In addition, Fairus wrote "enjoy the latest movies, books, and TV programs, When they learn English" (Fairus, op3B). Thus, English for leisure for them concerned travelling and enjoying good shows and books.

Thirdly, some of the participants opened up to English for a noble and religious course. Fatinmalik penned it beautifully in her online posting:

so this [English language] is the universal language will open you doors other cultures and civilizations and you can navigate our thoughts and our Islamic culture great to all over the world and participate in spreading Islam is the religion of love and peace the change misconception held by the West for our religion (Fatinmalik, op3B)

As can be understood from the above data extract, through the use of English, Fatinmalik intended to eliminate the westerners' misunderstandings about Islam. Basri also announced that he would tell people about "the truth!" because "some people think wrong about people with beard...scared" (Basri, int_1). In fact, Faizah felt the frustration when she could not explain to a Taiwanese friend who was interested in Islam due to her lack of good command of the English language. She sheepishly admitted that "it was such a waste because I could not explain]" (Faizah, int_1). All in all, these participants felt that being a universal language, English could help spread the good word about Islam to all around the world.

Next, having an acceptable command of English can earn the person respect. This comes from the thoughts of Fairus and Faizal. Fairus attached a very positive opinion of her countrymen/women who can speak English. She said that "when we see Libyan person speaking English, something err...something big" (Fairus, int_1). Fairus grew up with that notion while Faizal visualised himself being a lecturer and it would be very important for him to be able to speak or use English. This is what he had to say in interview 1:

It is difficult when students ask me something, I said I don't know. It means the respect will go.

I see, the respect.

\section{Yes. So I must [learn English]}

You must. Yes. Definitely. Ok.

(Faizal, int_1)

In short, these participants equated having a good command of English to having better respect from people around them.

The last point that motivates the participants to be good in English is the need to communicate and understand. Many participants like Basri, Fairus, Faizah, Fatinmalik, and Imran conveyed that English is used to ease communication and reach understanding because as stated by Fatinmalik, "the world has become a small village and in order to live in peace and love must communicate and reach an understanding" (Fatinmalik, 
op3B). Along the same line, Faizah expressed that "to increase capacity and opportunity get along to international world need English" (Faizah, op6B). Furthermore, they also realised that they would be meeting different people. Fatinmalik talked about communicating with "some friends who are not Iraqian" (Fatinmalik, int_1), while Basri pointed out that "but with the people who do not know Arabic so I have to talk with English" (Basri, int_1).

To summarise, the subtheme of 'motivation to' encompasses several sub-subthemes. These are mostly the aspirations that the participants hoped to achieve. They aspired to do well in their academic, and enjoy shows and books, and travel around the world. They also felt that being good in English would help them to spread the good teachings of Islam, earn them respect, and also to communicate and understand the diverse people around them.

\subsubsection{Motivation from}
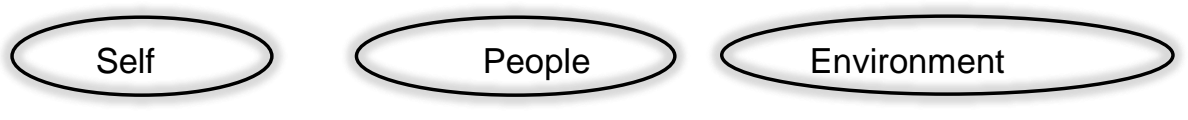

As illuminated, investment is not just about motivation to achieve something. Investment pulls in elements that are related to the participants' social, cultural (academic) activities and experiences. Thus, the subthemes for 'motivation from' are self, people and environment. This section presents all the sub-subthemes under these three subthemes that give insights into the social activity and experiences of the participants that bring out their investment.

The first subtheme is self. Linking this to the earlier mentioned dichotomies, 'self' is parallel to intrinsic motivation where the pull comes from within a person. Hence, 'self' includes the goal set, attitude in life as well as towards English and their own experiences. A few participants mainly Fatinmalik, Nabil and Faizal were very adamant about learning English. Nabil, for example, mentioned the enthusiasm in becoming good in English twice in his weekly reflections and once in interview 1. One of them proposed a way of doing it: "My goal now want mingle more with who can speak English" (Nabil, op4B). Faizal even prioritised English over his master's degree. He said, "When I came to here, I told my parents, most important for me I learn English. Even master I don't have like the same courage to study" (Faizal, int_1).

Other participants did not verbalise their strong intrinsic motivation like Nabil and Faizal did. Others' surfaced through their accounts of their positive attitudes towards life and English. Among the participants, two of them stood out in their positive outlook on life. How when faced with hardships they still moved on. Faizah relayed how she overcame her problem in mastering the Moroccan Arabic language when she studied in Morocco for her master's degree. She stayed with a Moroccan family and all she did was "learn, talk with [the] family and talk, talk". Then after one month she announced that she could manage the language and "until now I cannot forget the Morocco" (Faizah, int_1). Fatinmalik, on the other hand, had to handle her four children singlehandedly in Malaysia as her husband could not leave his teaching job in Iraq. They stayed in Kajang and she travelled to UKM every day by bus. Sometimes she would go back home during lunch breaks to serve lunch to her children and come back for late afternoon class. There were days when she had to take a taxi (Fatinmalik, int_1). On top of that, she was burdened with her children's visa problem because at one time, Iraqi children could not be given the status as dependents to their father or mother who was studying in Malaysia (Fatinmalik, op9A). Some children were sent home but not hers. She went to see the person-incharge in UKM to voice out her problem (later conversation on 13 December, 2012). When asked about this later after the study, the problem was already settled and all her children stayed with her in Malaysia.

Most of the participants showed positive attitude towards English. This is clearly declared by their lecturers. $\mathrm{Dr}$ Farah said that the ELPC students (including the 9 participants) had "the learning attitude. I would say the right attitude" (Dr. Farah int). While Dr. Farah called it the right attitude, Dr. Kaseh just branded it as "This attitude". She then elaborated saying that "they are not scared, they are very bold. They are not shy at all. Even if it is broken English, they don't really care" (Dr.Kaseh_int). The adjectives supplied by Dr. Kaseh echoed in the participants' confessions. Basri listed "don't be ashamed...to speak English and to talk with the teacher and classmates" as the first rule of learning English (Basri, op3A) while Fatinmalik plainly stated to "not [be] shy to speak English" (Fatinmalik, op3A). In a similar vein, Faizal proved that he was unperturbed when making mistakes by exclaiming "even wrong, I will ask and know the right words and I say it" (Faizal, int_1). All in all, although differently worded, Basri, Fatinmalik and Faizal presented the gem that best summarised their positive attitude. It can be concluded that all boils down to being willing (Faizah, op3A; Basri, op3A; Nabil, op3A). The discussion on self thus far can be seen as essentialising on their inner strength.

Another aspect of self is the experiences which might have contributed to the inner strength of the participants. 
These participants have gone through their lives and some parts of their experiences left them with a thought that they should learn English. The most interesting is Faizal's experience during the war in Baghdad. He relayed the story about how his father's ability to converse in English had saved them all. This is how the story goes:

We stay in dangerous region in Baghdad. So, sometimes, not, one time I remember that American knocked the door but very strong, he [Faizal's father] opened the door he said he know American...he talked with them "What you want?", he said to him, "Just switch off the light" because they don't want anybody to see them in the street. If he don't know English, may be they broke the door and come to broke the light (Faizal, int_1)

Fairus said that she had always been in awe with "journalists from $B B C$, like big channel from big country they reply in faster English" (Fairus, int_1) when they came to report on the war in Libya. Basri, on the other hand, wanted to learn English when he experienced difficulty in communication when he first arrived in Malaysia (Basri, int_1). Besides that, previous job experience also could make one need to master English. Nabil shared his working experience in which he had to use English: "I know design websites and also you know forum websites. I make it like this. I worked before with companies so I was all in English websites" (Nabil, int_1). Faizal was provoked when the interviewer during his first job interview said: "how come you engineering you don't know English" (Faizal, int_1). He got the job and worked there for 3 months before he decided to further his study.

The next subtheme for 'motivation from' is encouragement from the people around the participants. There are only a few direct mentions on the people who have motivated them. Basri, Fairus, Faizal and Imran specified the wife (Basri, int_1), father (Fairus, int_1) and lecturers (Fairus, op1B), parents (Faizal) and friend (Imran, op6B), as directly encouraging them in their language learning. However, there are countless of people, for example, friends, good speakers, lecturers, foreigners (international students) and even anyone, who have indirectly motivated them to use English. Looking into the ways on how encouragement was given by these people to the participants, it could be summarised that there are direct and indirect motivation. The former refers to the verbal motivation given by the participants' wife, father, lecturers, parents and friend. Whereas, the latter speaks of the practical motivation given by the people.

To illustrate, verbal or direct motivation is when Basri relayed how his wife supported him by being his 'mirror':

She supported me ... 'Good. You good. You need English', sometimes, 'you are good in English,' so I ...sometimes you need mirror... to tell you your level now. I feel that but you need someone to tell you. She said, 'good, you are good now' (Basri, int_1)

Moreover, verbal or direct motivation can be seen when Fairus' father told her to follow the footsteps of Libyans who can speak English: "see them, why you didn't make like them" (Fairus, int_1). As for practical or indirect motivation, it describes how the people have joined them in practising English and lent a hand when help was sought (for example, answering question). They motivated them by not demotivating them. In other words, they kept the conversation going and never turned down any request for help (for example, when the participants asked for directions).

The last subtheme concerns the motivation that comes from the environment. In summary, investment stems from 'motivation to' and 'motivation from'. The former reflects the multiple desires that the participants have while the latter shows the experiences and elements from within the participants that became the push factors for them to exercise their agency.

\subsubsection{Discussion for Theme 2 - Investment}

Investment is closely linked to motivation as both refer to the pull and push factors that move a person to perform. Motivation is by far the most popular explanation for student performance or lack of it (Scovel, 2001). Lantolf (2000) asserts that a person behaves in accordance with his/her social and cultural surrounding. He and Pavlenko (2001) then add that human behaviour has its roots in history too. Thus, the findings suggest that these participants put in extra efforts and took up challenges due to the three elements (social, cultural and historical). Socially, they were motivated to learn English because they wanted to communicate and understand, to travel to places and enjoy books or shows, and also to be respected. Culturally (this is seen as the culture in academic because their main objective here was to pursue their postgraduate degree or at least based on their short-term goal was to pass ELPC), they wanted to understand the language of science and most of them needed to write their thesis in English. 'History' can be linked to the participants' experiences back in their own country and also for some of them, based on their experience learning another language. Thus, social, cultural and historical factors work as the impetus for motivation or investment that when translated into behaviour that is acted within the limitations in the environment would show the person's agency. 


\subsection{Theme 3 - Imagined community}

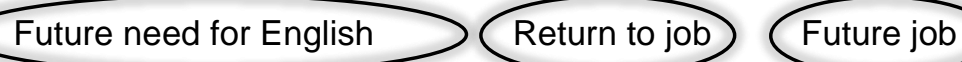

As the name suggests, imagined community is where the participants visualise they are going to be in the near future, at least after their course of study is over. This includes their need for English in the later chapter of their lives, how they are going to upgrade themselves when they return to their existing job after the postgraduate degree, and also future employment. Imagined community is a notion that plays a role in the agency exercised by the participants. It can actually be subsumed under 'Motivation to' - Investment, as they share the same concept where the participants exercise their agency in order to achieve or fulfill a goal. However, there are differences in terms of time and degree of importance. The sub-subthemes for 'motivation to' include goals to achieve success in academic, leisure, to gain respect and also to spread Islam. On the other hand, the goals for 'imagined community' are career-based. Thus, in terms of time, the goals for 'motivation to' can be short-term or long-term whereas, for 'imagined community', the goals are considered long-term as they will only be encountered after their postgraduate degree is over. Furthermore, being based on career or at least the future, 'imagined community' bears a higher degree of importance as pursuing a postgraduate degree could be a stepping stone for a better career and future, and thus be in a better community.

The first subtheme for 'imagined community' is future need for English. It refers to the needs which are not immediate. For instance, Basri announced that he would be going back to Algeria after his $\mathrm{PhD}$ and he would "need to surf internet, talk with international students, international people...I need English" (Basri, int_1). As for Mohsin, he intended to pursue his "education in another country...Australia or Netherlands" (Mohsin, int_2). There are other needs but they are related to their career which are discussed in the next few paragraphs.

The second subtheme is upgrading themselves when they return to their existing job. Two of the participants were on study leave from their lecturer position back in their home country. Shamsulwahab and Fatinmalik would be going back to their college and university, respectively, in Iraq once they finish their PhD. Shamsulwahab admitted that he would not be able to teach his subject in full English but he wished to expose his students to English. These are the exchanges from interview 1:

So what do you plan to do then, when you go back?

\section{I cannot teach in English}

Why?

Because there are students cannot understand what I say but we try to put more speaking in English, more time and for example if before I come in to Malaysia, I don't enough speaking English in any class. I hope or I try after return to my country and to my college and speak in English about 10 minutes or 15 minutes with students...to...what can I say

To make them familiar with the language

Yeah. To improve my language and to high their level of the students in speaking in English. (Shamsulwahab, int_1)

In the same light, Fatinmalik did not mention about teaching her Mathematics subject in English but she touched on how knowing English can make her a good supervisor to her students. She shared her intention in interview 1:

I need to take some students to supervise them so of course our thesis in Iraq and master and PhD in English for mathematics. So of course I need to know exactly what's the meaning...all the meaning of every journal, every conference in order I can help my students.

int_1)

(Fatinmalik,

In addition, Fatinmalik also envisioned that her social obligations for her university would also require her to use English. This is evinced in the data extract as follows:

\section{Iraqian people know Arabic no problem but when people coming}

Foreigner coming and visiting your university, professor from this country that country

Yes yes. That's exactly (Fatinmalik, int_1)

The need to use English was also envisaged as important by other participants who would only apply for a job 
once they graduate in the third subtheme entitled 'future job'. Most of them would like to be a lecturer in their own field. Nabil would love to go back to his alma mater - a university that used a lot of English. He said, "many Iraqi teacher have PhD in computer science and they teaching in English in university of Bahrain. I am interested to be like them". Furthermore, he also intended to design websites which are "mostly English" (Nabil, int_1). Moreover, Faizah added that as a lecturer, she would use English in seminars, international conferences, and also in writing articles for international audience (Faizah, int_1). On the other hand, Fairus was banking on the idea that with English, one can land a good-paying job. She wrote, "get work in a multinational company within their home country which give a higher salary to the person who have English" (Fairus, op3B). Unlike Fairus, Faizal's idea of using English in his future job as an engineer cum a lecturer is more of a practical issue. He said the information in the manuals for any device is in English and none in Arabic (Faizal, int_1).

In summary, the participants' imagined communities are mostly career-related. Some would be going back to their jobs which they left temporarily to pursue their studies while many planned to start working or even continue to study after finishing their postgraduate degree in Malaysia. All in all, they could see that their future could be better with better command of the English language.

\subsubsection{Discussion for Theme 3 - Imagined community}

The data from this study revealed participants exercising their agency in relation to the 'imagined community'. Imagined community as presented in the literature can cause action or inaction among the participants. For example, a study by Trent (2008) showed how the Chinese worked on upgrading their English because they wanted to be a part of the Christian group with the church. On the other hand, Arkoudis and Love (2008) discovered that a group of Chinese learning Mathematics in Australia was not interested to better their English language because they could see that they would later be in a working community that conversed in Chinese and not English when it comes to Mathematics. Trent's (2008) study shows that the imagined community moves the participants to take action while Arkoudis and Love's (2008) study highlights the inaction of the participants due to their imagined community that harbours no interest in English. These two examples stress on the two contrasting types of relationships between language learning and imagined community. However, based on the findings for this study, the participants did what they could to be equipped with the English language in order to utilize this in their career/study later.

\section{SUMMARY AND CONCLUSION}

The process of exercising agency by the participants was portrayed through the discussion of the three themes. They showed their agency in terms of the efforts taken and challenges met. From the presentation of data, it can be surmised that the factors of investment and imagined community have played a big role to make them exercise their agency in advancing and challenging themselves in their language learning.

Although all the three notions concur with the extant literature, the findings from this study highlight 'experience' as the impetus for investment for their English language learning.

\section{REFERENCE LIST}

Arkoudis, S., \& Love, K. (2008). Imagined communities in senior school mathematics: Beyond issues of English language ability. The Asia Pacific Communication: Special issue Chinese students: Perspectives on their social, cognitive, and linguistics investment in English medium interaction, 18 (1), 71-90.

Bandura, Albert. (2001). Social Cognitive Theory: An Agentic Perspective. Annual Review Psychology, 52, 126.

Bandura, Albert. (2005). The evolution of social cognitive theory. In K. G. Smith \& M. A. Hitt (Eds.), Great Minds in Management (pp. 9-35). Oxford: Oxford University Press.

Bandura, Albert. (2006). Toward a Psychology of Human Agency. Perspectives on Psychological Science, 1(2), 164-180.

Braun, Virginia, \& Clarke, Victoria. (2006). Using thematic analysis in psychology. Qualitative Research in Psychology, 3(2), 77-101.

Davies, B. (1990). Agency as a form of discursive practice. A classroom scene observed. British Journal of Sociology of Education, 11(3), 341-361.

Gu, M. (2008). Identity construction and investment transformation: College students from non-urban areas in 
China. The Asia Pacific Communication: Special issue Chinese students: Perspectives on their social, cognitive, and linguistics investment in English medium interaction, 18 (1), 49-70.

Kettle, M. (2005). Critical discourse analysis and hybrid texts: Analysing English as a second language (ESL). Melbourne Studies in Education, 46(2), 87-105.

Lantolf, James P. (2000). Introducing Sociocultural Theory Sociocultural Theory and Second Language Learning (pp. 1-26). Oxford: Oxford University Press.

Lantolf, James P, \& Pavlenko, Aneta. (2001). (S)econd (L)anguage (A)ctivity theory: understanding second language learners as people. In M. P. Breen (Ed.), Learner Contributions to Language Learning: New Directions in Research (pp. 141-158). Singapore: Pearson Education Asia Pte Ltd.

Noor Saazai, M.S, Yunus, M.M, Embi, M. A, \& Yasin, M.S.M. (2014). Conducting online posting activity on a social networking site (SNS) to replace traditional learner diaries. In M. Orleans (Ed.), Cases on Critical and Qualitative Perspectives in Online Higher Education (pp. 489-508). USA: IGI Global.

Norton, B. (1997). Language, identity and the ownership of English. TESOL Quarterly 31: 409-487.

Oxford, R. L. (2011). Strategies for learning a second or foreign language. Language Teaching, 44(02), 167180. doi: $10.1017 / \mathrm{s} 0261444810000492$

Pavlenko, A. \& Blackledge, A. (2004). Negotiation of Identities in Multilingual Contexts. Clevedon: Multilingual Matters Ltd.

Pierce, B.N. (1995). Social identity, investment, and language learning. TESOL Quarterly, 29(1), 9-31.

Scovel, Tom. (2001). Learning New Languages: A Guide to Second Language Acquisition. Canada: Heinle \& Heinle.

Tran, L.T. (2007). Journeys of Adaptation to Institutional Academic Practices: International Students in Higher Education. Melbourne: The University of Melbourne. PhD.

Trent, J. (2008). Promoting investment by Chinese learners in classroom discourse: Integrating content and language in the undergraduate classroom. The Asia Pacific Communication: Special issue Chinese students: Perspectives on their social, cognitive, and linguistics investment in English medium interaction, 18(1), 30-48. 
Appendix

\section{The 10 topics for online postings on Google+ circle}

Topic 1 : Your own English language learning experiences in your home country.

Topic 2 : The importance of English in your current studies in this $U$ and in the future (profession or career/personal life etc

Topic 3 :What do you think are the good and effective ways to learn English. List down or discuss the ways in two aspects: 1. good and effective ways to learn English in class and 2. good and effective ways to learn English out of class (not in class but outside - including at home, shopping mall, bus stop etc.)

$\underline{\text { Topic } 4}$ : (there are two parts to the topic)

1. Based on your observation of or discussion with other international students in this $U$ or other universities/learning institutions (your friends, your friends' friends, or just any international student you know or just met/saw), how, when, where and with whom did they use the English language?

2. Please share information on any ways or techniques (they used) that you find interesting?

Topic 5:Think of a favourite place in your country. Where is it? What is the name of the place? What do you do there? Who else goes there too? When do you go there? How do you go there? And any other information. (if you have a picture of it, please include)

Topic 6:Write about your favourite place in

1. Malaysia

2. this $U$

If you do not have any favourite place, then just write about any place that you have been to in Malaysia and this U. I am more interested in what you do in those places :-)

Topic 7 : Write about your opinion of an ideal or a perfect university/institution of learning. In other words, what do you think makes a perfect university?

$\underline{\text { Topic } 8}$ :If you had 1,000,000 (one million) USD, how would you use the money to improve your English?

Topic 9 :How do you prepare for your Speaking assignments, and what do you do to complete your Writing assignments?

$\underline{\text { Topic } 10}$ : In your opinion,

1. is the writing activity of online postings on Google+ for 10 weeks good for you?

2. if good, why is it good and how have you improved your English? if not good, why is it not good?

3. how can we make the activity of online postings better? 